\title{
Revitalization of the NASA Langley Research Center's Infrastructure
}

\author{
Erik S. Weiser ${ }^{1}$, Michael D. Mastaler ${ }^{2}$, Stephen J. Craft ${ }^{3}$, Jerome T. Kegelman ${ }^{4}$, \\ Drew J. Hope ${ }^{5}$, and Cathy H. Mangum ${ }^{6}$ \\ NASA Langley Research Center, Hampton, Virginia 23681
}

\begin{abstract}
The NASA Langley Research Center (Langley) was founded in 1917 as the nation's first civilian aeronautical research facility and NASA's first field center. For nearly 100 years, Langley has made significant contributions to the Aeronautics, Space Exploration, and Earth Science missions through research, technology, and engineering core competencies in aerosciences, materials, structures, the characterization of earth and planetary atmospheres and, more recently, in technologies associated with entry, descent, and landing. An unfortunate but inevitable outcome of this rich history is an aging infrastructure where the longest serving building is close to 80 years old and the average building age is 44 years old. In the current environment, the continued operation and maintenance of this aging and often inefficient infrastructure presents a real challenge to Center leadership in the trade space of sustaining infrastructure versus not investing in future capabilities. To address this issue, the Center has developed a forward looking revitalization strategy that ties future core competencies and technical capabilities to the Center Master Facility Plan to maintain a viable Center well into the future. This paper documents Langley's revitalization strategy which integrates the Center's missions, the Langley 2050 vision, the Center Master Facility Plan, and the “New Town” repair-byreplacement program through the leadership of the Vibrant Transformation to Advance Langley (ViTAL) Team.
\end{abstract}

\section{Nomenclature}

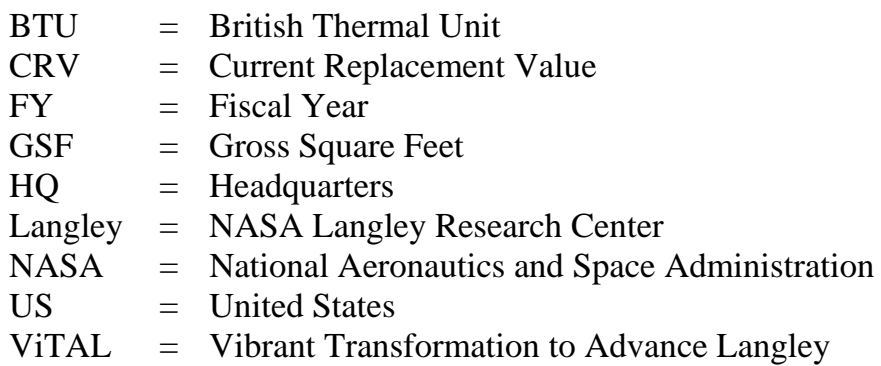

\section{Introduction}

The NASA Langley Research Center was founded in 1917 by the National Advisory Committee for Aeronautics and became one of four NASA field centers established in 1958. For nearly a century, Langley has

\footnotetext{
${ }^{1}$ Associate Director, Research Directorate, Mail Stop 147

${ }^{2}$ Head, Revitalization Office, Center Operations Directorate, Mail Stop 147

${ }^{3}$ Deputy Director, Strategic Relations Office, Mail Stop 147

${ }^{4}$ Chief Engineer, Ground Facilities and Testing Directorate, Mail Stop 147

${ }^{5}$ Associate Director, Engineering Directorate, Mail Stop 432

${ }^{6}$ ViTAL Team Lead and Chief Information Officer, Mail Stop 147
} 
pioneered research and development in Aeronautics, Space Exploration, and Earth Science. All aircraft developed in the United States (US) have been benefitted from the analytical and experimental work done by the researchers and engineers at Langley utilizing a complete suite of wind tunnels that span the speed regime from subsonic to hypersonic, novel materials and structures, and flight research systems. New instrument systems for measuring and characterizing the Earth's atmosphere are created from breakthroughs in the laboratory and developed into fully-operational, space-based instruments. The ability to work the spectrum of basic research to systems application gives the center a proven history of developing technology and integrating technologies into flight systems. However, a significant portion of the infrastructure and buildings necessary to meet future mission and program milestones is aging, inefficient, and often unreliable, and, at this point, Langley's longest serving building is over 80 years old and the average building age is 44 years old. This trend in aging infrastructure is not unique to Langley, NASA, or any of the numerous government installations across the US. Being ready to lead and make future contributions, adapting to evolving mission and program requirements, and including societal and technology improvements are key drivers for a revitalization strategy and implementation plan.

For several years now, NASA and Langley have been encouraged by the Executive (Office of Management and Budget) and Legislative (Congress) Branches of the federal government to reduce infrastructure costs. Most recently, Congress reinforced this position with language in the NASA Authorization Act of 2010 stating that NASA was, “...'holding onto' facilities and capabilities scaled to another era." ${ }^{1}$ The aging infrastructure, push to consolidate, and continuing budget challenges have created an environment where meeting Agency mission goals and objectives has become more difficult and costly. The National Research Council's Committee on the Assessment of NASA Laboratory Capabilities noted in their 2010 report, "Many researchers expressed the belief that NASA will not be able to maintain its core capabilities let alone to develop them." ${ }^{2}$ As a result, Langley leadership expedited previous plans to address aging infrastructure through a repair-by-replacement program called "New Town," and updated and integrated this strategy into the 2010 version of the Center Master Facility Plan. The overarching goals of the Center Master Facility Plan are to sustain or enhance the Center's core capabilities through repair-by-replacement or rehabilitating existing buildings based on a credible business case. The goals included reducing the footprint of the Center, incorporating a healthy, friendly environment similar to a college campus, and transforming the remaining infrastructure to be energy efficient, sustainable, and adaptable to changing mission and societal needs. These goals are fundamental to ensuring that Langley remains a critical research and development Center for the Agency and the Nation well into the $21^{\text {st }}$ Century.

In early 2011, the Langley Center Director designated a new team, the Vibrant Transformation to Advance Langley (ViTAL) team, to integrate the Center's mission with the Center Master Facility Plan. The team was also asked to convey the need and importance of this revitalization strategy to Center employees.

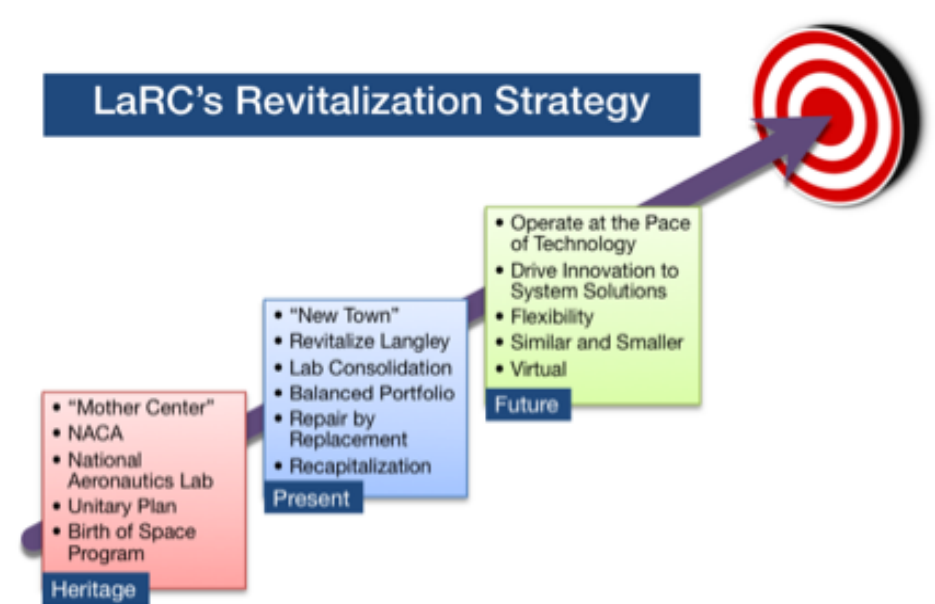

Figure 1. Revitalization Strategy. Honoring our past accomplishments, building on our current capabilities, and enabling our future opportunities.

\section{Revitalization Goals}

To ensure future technical relevance and long-term distinguished research, bold action is required now. The goals of the pioneering revitalization strategy, Fig. 1, include enabling new, exciting missions, creating the Langley of 2050, and reducing infrastructure and other costs. 


\section{A. Enabling Future Missions and Sustaining a Diversified Portfolio}

Langley's value proposition to the Nation is the knowledge and technology provided through the breadth and depth of our core competencies in: aerosciences; structures and materials; systems analysis; earth sciences; and entry, descent, and landing; couple with systems engineering to provide multidisciplinary integrated solutions, Fig. 2. These core competencies and capabilities are used as a focal point to answer the grand challenges underlying NASA's missions in Aeronautics, Human Exploration and Operations, Science, and Space Technology. Langley maintains a diversified portfolio across these primary NASA missions by successfully leveraging our multidisciplinary capabilities to maximize leadership and contributions to the Agency missions, Fig. 3. Coupled with the Langley core capabilities are the Center's ability to collaborate with external partners in industry, universities, and other Government agencies. These partnerships enhance our mission output and continually create and incubate new ideas and concepts. They can supplement Agency programs and projects, drive innovations and develop advanced technologies. The Center infrastructure is central to this value proposition, and the

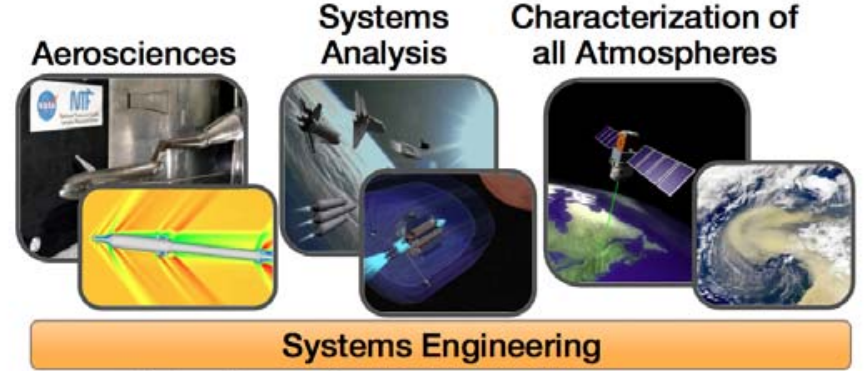

Entry, Descent \& Landing

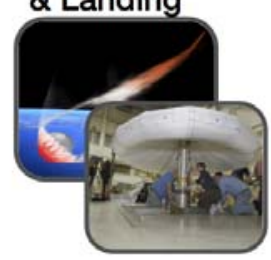

Structures \& Materials

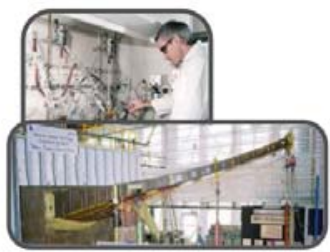

Figure 2. Langley Core Competencies. Langley's core capabilities span: aerosciences; systems analysis; characterization of all atmospheres; entry, descent, and landing; and, structures and materials; with systems engineering spanning all disciplines. revitalization of the infrastructure is critical to sustaining and growing Langley's portfolio.

\section{B. Creating the Langley of $\mathbf{2 0 5 0}$ and Beyond}

Langley's revitalization strategy embraces our heritage while enhancing prospects for future missions. Being mindful of expected societal changes, establishing a healthy and stimulating work environment and providing suitable and effective tools will be key to attracting brilliant young professionals to support the Langley of 2050. Future NASA missions, Fig. 3, will be achieved by advances in collaborative computational modeling and technology development across each Langley core competency. Improvements in information technology (extreme connectivity) will enable Langley to work with a far greater number of external and international partners. Virtual presence and improvements in modeling techniques and information processing will combine with a greater societal ability to leverage research and engineering tools for accelerated worldwide technology development.

Meeting these challenges and continuing to remain a preeminent research and development center through the year 2050 and beyond will require building advanced, flexible, and sustainable research and development facilities. These facilities will require state-of-the-art equipment and an interconnected information technology infrastructure to achieve the future NASA mission and to attract, retain, and promote the brightest minds necessary to create the future.

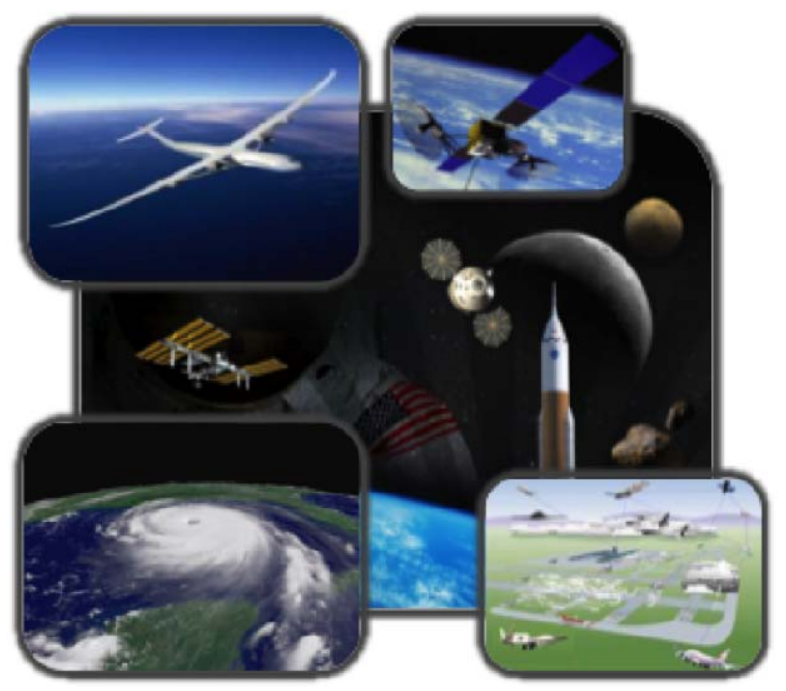

Figure 3. Future NASA Missions. Extend and sustain human activities across the solar system, expand scientific understanding of the earth and the universe in which we live, and advance aeronautics research for societal benefit. 


\section{Reducing Infrastructure and Costs}

Guiding Langley strategic formulation and plans are nearer-term NASA goals and objectives for infrastructure operation and costs. These goals and objectives are specific for Current Replacement Value (CRV) and energy and water consumption, and the guideline for CRV implies a change to foot print. For CRV, the goal is to reduce from the 2008 baseline of $\$ 3.3 \mathrm{~B}$, and the objectives are to reduce $10 \%$ by 2020 and $15 \%$ by 2050 (from the Agency's "Slow and Steady" recapitalization model). Langley has been very aggressive with demolition and is on track to reduce CRV to $\$ 2.8 \mathrm{~B}$ by 2020 . This $15 \%$ reduction in CRV far exceeds the 2020 objective, and this "success" will not limit future demolition plans that might be necessary as we move forward. For energy consumption, the goal is to reduce from the 2003 baseline of 126,000 British Thermal Unit per Gross Square Feet (BTU/GSF), and the objective is to reduce 30\% by 2015 in Goal Subject Buildings. ${ }^{3}$ Through the use of efficient lighting Center-wide, utilizing the first New Town building, demolition, and employee awareness, Langley is on track to achieve this objective, and we fully expect that energy consumption in 2015 will be down to approximately 88,200 BTU/GSF. For water consumption, the goal is to reduce from the 2007 baseline of 46 gallons/GSF, and the objective is to reduce $16 \%$ by $2015 .{ }^{4}$ Through the very active identification and repair of leaks, Langley is on track to reduce water consumption in 2015 to approximately 38 gallons/GSF. Finally, the hardest specific Agency objective for Langley to address is to increase the utilization of Renewable Source Energy to $7.5 \%$ by $2015 .{ }^{5}$ Langley will meet this objective through the continued purchase of renewable energy credits and by operating a photovoltaic field to supply energy to meet the needs of the Langley Badge and Pass Office.

The implied goal to reduce foot print is coupled with the reduction in CRV. Although there is not a specific objective, Langley has demolished 381,000 GSF since 2005 and is on track to reduce by 1,065,000 GSF through 2023. This amount is more than 25\% of the approximately 4,000,000 GSF Langley had in 2005.

The explicit benefit of reducing consumption and foot print is a decrease to the operations and maintenance cost burden the infrastructure places on the Center. The implicit benefit of these reductions will be a greater likelihood the Center will be able to invest in the new technical capability and skills required for the future.

\section{Approach}

To enable the revitalization strategy, the Center is developing a comprehensive future technical vision, revising the Center Master Facility Plan to build the capabilities necessary to sustain the competencies required for this vision, and utilizing the ViTAL Team to integrate and accelerate the implementation. The future technical vision includes a strategic evaluation of skills, workforce, tools, capabilities, and facilities required to meet Agency and Center missions. The Center Master Facility Plan is the controlling document that encompasses all aspects of the infrastructure strategy and the major component is the New Town Plan. ViTAL is a Center level team tasked with optimizing the Center Master Facility Plan to enable the future technical vision so that Langley will continue to meet the goals and objectives of the Agency beyond 2050.

\section{A. Future Technical Vision}

To begin envisioning the future Center, Langley formed several strategic technical teams to develop components of the types of research and development necessary to meet the goals and objectives of the Nation for the next 40 years. The teams incorporated several of NASA's strategic documents such as the Office of Chief Technologist's Technology Road Maps, Earth and Planetary Science Decadal Surveys, and the National Aeronautics Research and Development Policy and Plan ${ }^{6-8}$ These teams spanned Langley's core competencies and potential new areas of research and development and were also tasked with determining the facilities and capabilities required to address and resolve future technical challenges. This evaluation has now been extended to development, operational, and testing organizations, and ViTAL will aggregate and integrate the combined input from the various organizations into a comprehensive, forward looking set of technical capabilities and facility requirements. The evaluations are still continuing, but preliminary findings are: (1) physical testing will be required for at least the near future for research and integrated flight systems processing and qualification; (2) greater investments in computing environments and improvements in first-principles modeling and simulation techniques will allow Langley to reduce the amount of wind tunnel testing required for aerospace research and development; (3) modeling and synthesizing of nano- and bio-inspired materials will lead to lighter-weight, more efficient materials and structures; and, (4) the potential for increased virtual presence will allow for a greater level 
of remote testing and international collaboration. These requirements will then be integrated into the next version of the Center Master Facility Plan and a revised New Town Program.

\section{B. Center Master Facility Plan}

The Center Master Facility Plan provides a comprehensive presentation of how assets relate to the technical community, provides for the sustainable development of the Center and its facilities and infrastructure, and integrates with and supports the Center's planning and budgeting processes. Oversight for the Center Master Facility Plan is provided by the Center Director and NASA HQ.

The Center Master Facility Plan reflects and implements the Agency's facilities strategy objectives to sustain the ability to meet current and future mission requirements; accommodate technical capabilities in fewer, more efficient and cost-effective facilities; implement the "slow and steady" recapitalization model; and reduce CRV.. Implicit to the recapitalization model is a requirement to reduce facility inventory without any reduction in technical capability.

In 2009, Langley embarked on a bold planning initiative to strategically reposition its physical facilities and research campus for the 21st Century. The plan focuses on the future requirements of Langley while maintaining its tradition for technical excellence. The Center Master Facility Plan addresses the construction of new buildings necessary to support the Agency through the midpoint of the 21st Century, the renovation of buildings in a reasonable condition, and the removal of buildings in poor condition or not needed to meet NASA's mission. An additional critical element of the Center Master Facility Plan is the rehabilitation of the horizontal infrastructure (e.g., the electrical power distribution system) necessary for the future.

The Center Master Facility Plan also focuses on the overall reliability of the facilities and the ever-increasing operational and maintenance costs required to sustain an acceptable level of readiness. The Center Master Facility Plan will increase foot print by approximately 400,000 GSF of new construction and includes the renovation of approximately 285,000 GSF. The design and construction of the first five buildings will be phased over a 20-year period to minimize the need for major capital investment in any single year, and the demolition of deteriorated and underutilized facilities will be done concurrently with the new construction and renovation. The addition of newer, more efficient facilities and the demolition of older, costly buildings will significantly reduce the annual operations and maintenance burden for the Center.

\section{New Town Program}

The New Town Program is the Langley repair-by-replacement program which had its genesis in the late 1990s, was approved by NASA HQ in October 2010 as part of the Center Master Facility Plan, and will be implemented through the 2035 time frame. This infrastructure revitalization plan includes new facilities and labs to enable future experimental work, a commitment to current capability essential to our future, and the divestment of obsolete capability not needed for future work or capability with inherent aging-related operational inefficiencies and excessive maintenance requirements. All of the new infrastructure will be designed and constructed for increased sustainability through the Leadership in Energy and Environmental Design certification process and will require lower operational costs. The overarching principles to the New Town plan are to sustain and enhance the Center's core capabilities through repair-by-replacement or the rehabilitation of existing buildings where it makes sense, reducing the footprint of the Center to emphasize a campus environment that will integrate and accelerate research and development by co-locating diverse disciplines and capabilities, and to transform the infrastructure to be more efficient, green, and adaptable to changing mission and societal needs. These principles are

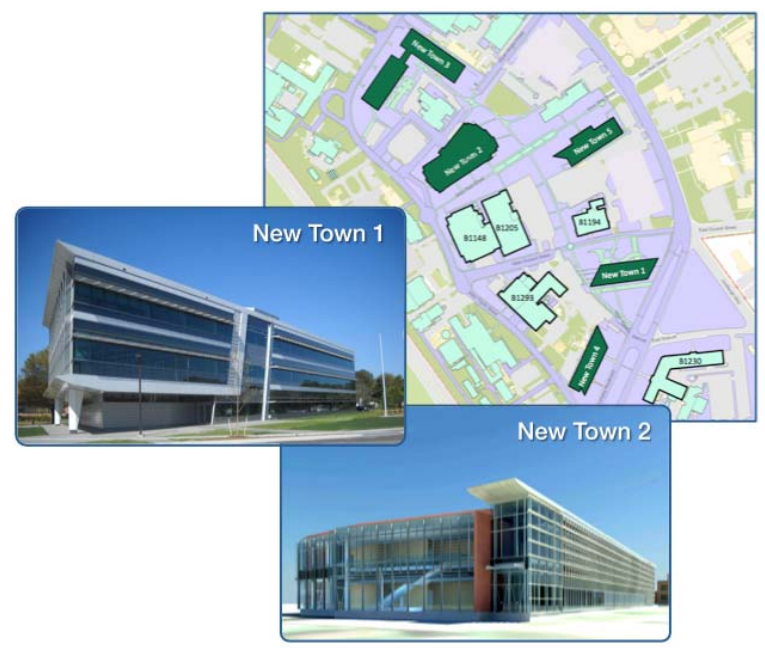

Figure 4. First Five Phases of New Town. New Town is a repair-by-replacement program that emphasizes a core campus environment to stimulate cross-disciplinary research and development. Shown are New Town 1, Langley Headquarters, and New Town 2, the Collaboration Center. 
fundamental to ensuring that Langley remains a critical research and development Center for the Agency and the Nation late into the $21^{\text {st }}$ Century.

The total New Town Program will consist of eight buildings, New Town (Phases 1-5) and the New Town Follow-on (Phases 6-8), Fig. 4. The first phase, Langley HQ, became operational in the summer of 2011 and Phase 2, the Collaboration Center, will begin construction in the spring of 2012. New Town Phase 3, the Measurement Sciences Lab, and Phase 4, the Materials and Structures Lab, are crucial to sustaining Langley core competencies, lab rightsizing, and revitalization. These two new research labs will be highly complex and technical in nature and will consolidate over 80 unique labs from five buildings into two adaptable configurations. Langley is also planning for future societal changes, including teleworking, hoteling, virtual labs, and remote presence, which are expected to reduce the need for office space. This anticipated future will drastically change the way buildings are used, compared to current Langley facilities, and the emphasis for New Town will be on designing and building shared, collaboration laboratory and office space.

Central to this strategy is the consolidation of new and renovated facilities within the New Town core campus area, Fig. 4. By achieving a greater concentration within the core area, New Town will bring more life and energy to the Center and walking (rather than driving) between buildings will be easier for staff and visitors. In addition, the core campus environment will promote cross-disciplinary research and development interactions between Center organizations. The New Town core area also brings a logic and order to the overall site plan and reserves specific areas of the campus for potential future uses or investment opportunities.

A fundamental aspect of the New Town Program is the business case. Langley's ability to develop a technical argument for revitalization is fairly easy, but securing funding for revitalization required a compelling and convincing financial argument and a reasonable payback period for the Agency. To do this, Langley developed the New Town business case that evaluated the costs to build new, to renovate, and to demolish against the operations and maintenance savings generated by locating personnel in more efficient, high-density space. For Langley, this quid pro quo case hinges on office space which is less costly to build, operate, and maintain and easier to populate. The business case convinced the Agency to initially invest in the Langley New Town administrative buildings, and the longer-term savings realized through the reduced infrastructure burden will allow additional investment in future technical infrastructure.

\section{ViTAL}

Although previous strategic plans were being implemented, Langley recognized the independent nature of these plans and chartered the ViTAL Team to integrate and accelerate them. ViTAL is tasked with melding the Center's mission with the Center Master Facility Plan, expediting cost savings options, and addressing alternate work arrangements to provide a more coherent implementation of the revitalization strategy.

ViTAL's guiding principles are to nurture Langley's core competencies to meet future mission requirements, to ensure the infrastructure is efficient, adaptable, and sustainable, and to actively manage the Center's transformation through effective communication and employee involvement. The benefits of success to the Center and NASA will be sustained and new technical capabilities that are adaptable to new and evolving mission requirements. Langley will improve the flexibility and rightsizing of the laboratories and office spaces by removing underutilized, redundant and/or inefficient facilities, labs, equipment, and systems.

\section{Integrating the Plans and Expediting Cost Saving}

ViTAL is developing an integrated infrastructure revitalization strategy that includes new facilities and labs to enable future experimental work, a commitment to current capability essential to our future, and the divestment of obsolete capability not needed for future work or capability with inherent aging-related operational inefficiencies and excessive maintenance requirements. Future investment and growth areas will be evaluated and will include items such as new enabling capability, timing, mission impact, capability requirements, and impact to the New Town Program and the Center Master Facility Plan. Capability divestment plans will be developed based on the strategic requirements of the Center to complete the Agency mission and will include items such as timing, impact to work force, impact to contracts, dollars required to do divestment and a communications and change management strategy.

An early success has been the revision of the previous plan for the unoccupied wing of Langley's NonDestructive Evaluation Laboratory. The project was originally planned as rehabilitation into office space with funding though the Agency's FY16 Recapitalization Program. ViTAL identified the greater need for renovated laboratory space, revised the plan, and advocated for funding through the FY14 Construction of Facilities 
Program. This revision will address ViTAL's push for efficient and effective laboratory capability, accelerate the relocation of personnel from a poor quality, high cost location, and will allow the Center to save \$350k by avoiding maintenance costs for an inferior building. This relocation will greatly improve the technical capability associated with non-intrusive diagnostic measurements and Langley's ability to meet the NASA mission.

ViTAL is also accelerating previously approved plans to address budget challenges, one of which is an expected decrease of the maintenance and utilities budget by $25 \%$ through the next six years. ViTAL accelerated the demolition of a large office building by five years which will save the Center $\$ 1.1 \mathrm{M}$ over that five-year period. ViTAL is also working to expedite cost savings by augmenting the previous demolition plans. When possible, ViTAL is relocating personnel to vacate a building and save recurring annual maintenance and utilities costs which generally run $\$ 6$ per GSF. With the one-time cost of demo at approximately $\$ 10$ per GSF, building demolition provides a very quick payback.

\section{Alternate Work Environments}

In addition to evaluating investments and divestments, the ViTAL Team is also assessing alternative work arrangements. Terms like teleworking, telecommuting, hoteling, and hot-desking are all used to refer to work done outside of the traditional on-site work environment. Alternate work strategies are important to meeting future mission requirements, attracting the next generation of workforce, and reducing infrastructure costs. Although small now, the percentage of federal employees taking advantage of alternative work arrangements is rising. Surprisingly, $61 \%$ of federal employees are considered eligible for telecommuting, and only $5.2 \%$ do on a regular basis. Federal budget pressures and government mandates for the federal workforce, including the Telecommute $\mathrm{Act}^{9}$ and others, emphasize sustainability, continuity of operations, shrinking technology replacement cycles, and cloud computing as primary drivers of change.

According to several surveys, benefits to the employer include an average $27 \%$ increase in productivity on telecommuting days due to fewer interruptions and wasted time in meetings. Adapting alternative work arrangements will also allow Langley to broaden the geographic talent pool. Flexible work hours enable a better work life balance, improved morale, and added job satisfaction. Behaviors and best practices developed through telecommuting will help Langley engage in additional worldwide collaboration in research and engineering. Advantages for employees include a greater ability to concentrate, more time to spend with family due to reduced travel times and less auto maintenance and fuel costs. For example, the average commute to Langley is 14.3 miles each way. Assuming an individual telecommutes two days per week, the average savings for fuel cost amounts to approximately $\$ 500$ per year.

Looking forward, workforce and workplace flexibility will be an important component of Langley's strategy. Continued emphasis on cost containment and reducing footprint, along with recognizing the needs of an emerging tech-savvy labor force, highlight the changes that will need to be implemented.

\section{Risks of Not Revitalizing}

The risk to Langley of not implementing the revitalization strategy will be far reaching. The most significant result will be the erosion of technical relevance and the decreased ability to lead and contribute to Agency missions. Pushing more institutional and infrastructure costs to programs and projects will result in less mission funding available to do research, idea and concept generation, exploration, testing, and validation. A high institutional burden increases the cost to conduct research and development and will directly impact our ability to attract collaborators, partners, and reimbursable business. The ability to maintain and utilize legacy facilities and equipment will be extremely difficult with expected budget guidelines and will force the Center to adopt a nonsustainable "run-to-fail" operational model that will impact reliability and our ability to deliver on our commitments. Finally, continuing to maintain and use legacy equipment and facilities will hinder Langley's ability to invest limited funding in new capabilities and equipment that are essential for our future.

\section{Conclusion}

Langley has an integrated, revitalization strategy that is reinvigorating our core competencies to meet the future missions of the Agency while actively addressing the aging infrastructure issues and reducing the operational costs of the Center. When fully implemented, the revitalized Langley will be even more responsive and adaptive to evolving programs and projects and will contain new technical capabilities and facilities that are 
efficient, effective, and require less funding to operate and maintain. As a Center, Langley will have an increased ability to continue its world-class, multi-disciplinary research and development with global collaborators and partners. Langley's vision of on-demand air mobility, access to space for everyone, and understanding of climate change will be enabled through this strategy, Fig. 5. At an individual level, the employees of Langley will continue to innovate and conduct the creative and collaborative research and development necessary to make significant contributions to society.

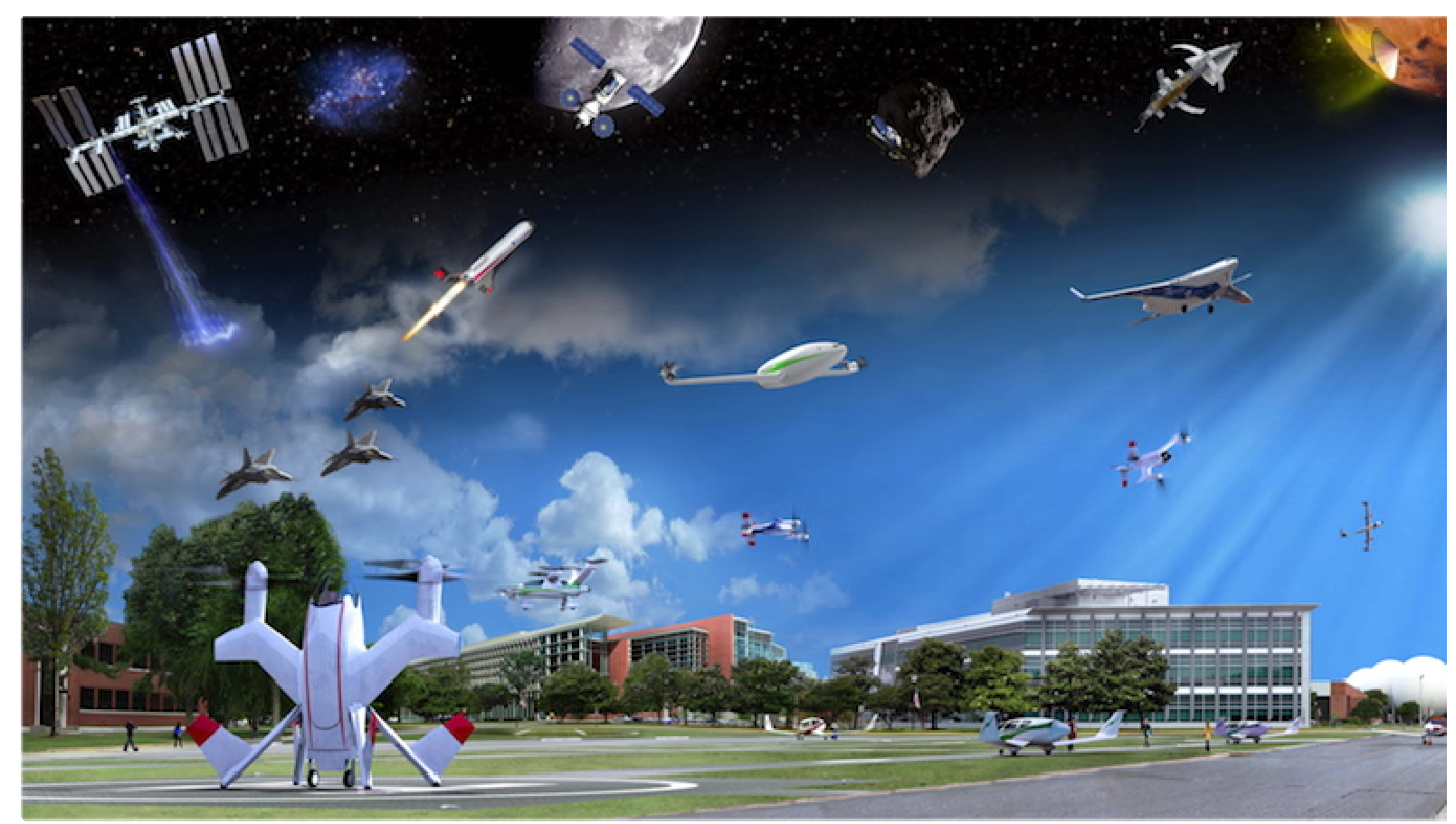

Figure 5. Langley of the Future. 


\section{Acknowledgments}

The ViTAL Team would like to acknowledge several people at the Langley Research Center. George Finelli, Chris Mouring, Tom Quenville, Cheryl Allen, and Rod Harris from the Center Operations Directorate provided the strategic planning foundation that proceeded ViTAL activities. Charles Harris, Research Directorate, provided the impetus and encouragement for the research teams that developed the future technical visions. Damodar Ambur, Ground Facilities and Testing Directorate, provided insightful recommendations to the development of this paper.

The ViTAL Team also would like to acknowledge Jerry Kegelman, Charles Harris, Rich Antcliff, Dennis Bushnell, and Doug Dwoyer for their evaluation and white paper describing $21^{\text {st }}$ Century labs.

\section{References}

${ }^{1}$ NASA Authorization Act of 2010, 111 ${ }^{\text {th }}$ Congress, Section 1101, Public Law 111-267, October 2010.

${ }^{2}$ Best, J. T., Reagan, J. B., et al, Capabilities for the Future: An Assessment of NASA Laboratories for Basic Research, Committee on the Assessment of NASA Laboratory Capabilities. The National Academies Press. Washington D.C. 2010. Pg. 67-76.

${ }^{3}$ National Energy Conservation Policy Act, United States Code (Fully Amended) Title 42, 1978.

${ }^{4}$ Executive Order No. 13423, 3 C.F.R. 298, Strengthening Federal Environmental, Energy, and Transportation Management, January 2007.

${ }^{5}$ Executive Order No. 13514, 3 C.F.R. 298, Federal Leadership in Environmental, Energy, and Economic Performance, October 2009.

${ }^{6}$ Executive Order No. 13419, 3 C.F.R. 298, National Aeronautics Research and Development, December 2006.

${ }^{7}$ Squyres, S. "Vision and Voyages for Planetary Science in the Decade 2013 - 2022,” $42^{\text {nd }}$ Lunar and Planetary Science Conference, Houston, Texas, 2011.

${ }^{8}$ NASA Office of the Chief Technologist Space Technology Road Maps, http://www.nasa.gov/offices/oct/home/roadmaps/index.html.

${ }^{9}$ Telework Enhancement Act of 2010, 111 ${ }^{\text {th }}$ Congress, Public Law 111-292, December 2010. 